\title{
Banding of the Pulmonary Artery for Common Atrioventricular Canal
}

\author{
JANE SOMERVILLE, T. AGNEW, J. STARK, D. J. WATERSTON, E. ABERDEEN, R. E. \\ BONHAM CARTER, AND S. WAICH
}

\author{
From the Hospital for Sick Children, Great Ormond Street, London W.C.1 and the \\ Institute of Cardiology, London W.1
}

Muller and Dammann (1952a, b) showed that banding of the pulmonary artery was beneficial for infants with congestive heart failure resulting from ventricular septal defect, and subsequently others confirmed the therapeutic value of this procedure in this and allied lesions (Fowler et al., 1958; Morrow and Braunwald, 1961; Albert et al., 1961; Goldblatt et al., 1965). Gammelgaard and his colleagues (1961) found that patients with common atrioventricular canal were not helped by this operation and in Sirak, Hosier, and Clatworthy's series (1959) no patient with this lesion survived banding. Common atrioventricular canal was present in $12(9 \%)$ of 135 patients who had banding of the pulmonary artery at the Hospital for Sick Children, Great Ormond Street, from 1957 to 1964 . The selection of patients with common atrioventricular canal and the post-operative course have been examined in detail.

\section{MethodS AND TERMINOLOGY}

The terminology has been described elsewhere (Somerville, 1965). "Common atrioventricular canal" is used to describe the type of atrioventricular defect with an ostium primum defect above and functioning ventricular septal defect below cleft mitral and tricuspid valves. The diagnosis was only accepted after necropsy or following angiocardiographic demonstration of the typically deformed left ventricular outflow tract found in atrioventricular defects (Baron et al., 1964), together with evidence of a ventricular septal defect judged by contrast medium passing direct from left to right ventricle.

Twelve patients aged 2 months to 2 years 4 months at the time of operation were studied. Operative pressures were taken before and after banding of the pulmonary artery. Surviving patients were followed for

Received January 26, 1967.
4 to 9 years with serial electrocardiograms and chest radiographs. Post-operative cardiac catheterization was carried out on 6 patients in the National Heart Hospital. In each case, catheters were passed, usually from a saphenous vein, into both atria and ventricles. The banded pulmonary artery was crossed in 4 patients either by using a No. 5 Cournand catheter or by floating Portex tubing through a No. 7 or 8 catheter sited in the outflow tract of the right ventricle (Carr and Wells, 1966). The wedge pressure recorded in the pulmonary veins was taken as an approximate pulmonary artery pressure in the other two patients. Systemic arterial pressures were constantly monitored through T.F. 10 passed into the femoral artery and up into the abdominal aorta or common iliac artery. Pressures were recorded by Statham pressure transducers on a 4-channel direct writing Sanborn recorder. Oxygen saturations were measured using the Kipp Hæmoreflector. All patients had left and right ventricular Elema biplane angiography and left atrial cine-angiography was performed in five. Patients who died at operation or during that admission have been called "operative deaths" and deaths occurring after this period were classified as "late deaths".

\section{RESULTS}

Pre-operative Clinical State of Patients. Eight patients were female and four were male. Eleven were under 1 year of age: one female child was a mongol. The pre-operative clinical and hæmodynamic data have been summarized in Table $I$. Severe congestive heart failure with tachypnœa, tachycardia, feeding difficulty, hepatic enlargement, and cardiomegaly was present in each patient at the time of operation. Digitalis, diuretics, tube-feeding antibiotics, and oxygen therapy were started when the infants were first seen in failure, and the patients either failed to respond or had deteriorated on this medical therapy when banding was undertaken.

The physical signs in 9 patients suggested ven- 
TABLE I

SUMMARY OF PRE-OPERATIVE DATA ON 12 PATIENTS

\begin{tabular}{|c|c|c|c|c|c|c|c|c|c|c|c|c|c|c|c|c|c|}
\hline \multirow{3}{*}{ Patient } & \multirow{3}{*}{ Sex } & \multirow{3}{*}{ Age* } & \multirow{3}{*}{$\begin{array}{l}\text { Age at } \\
\text { opera- } \\
\text { tion }\end{array}$} & \multirow{3}{*}{$\begin{array}{l}\text { Age at } \\
\text { first } \\
\text { symp- } \\
\text { tom }\end{array}$} & \multirow{3}{*}{ Symptoms } & \multirow{3}{*}{$\begin{array}{c}\text { Pan- } \\
\text { systolic } \\
\text { mur- } \\
\text { mur }\end{array}$} & \multirow{3}{*}{$\begin{array}{c}\text { Dias- } \\
\text { tolic } \\
\text { mur- } \\
\text { mur }\end{array}$} & \multirow{3}{*}{$\begin{array}{c}\text { Ejec- } \\
\text { tion } \\
\text { click }\end{array}$} & \multirow{2}{*}{\multicolumn{2}{|c|}{ 2nd sound }} & \multicolumn{7}{|c|}{ Pre-operative catheter } \\
\hline & & & & & & & & & & & \multirow{2}{*}{\multicolumn{2}{|c|}{$\begin{array}{l}\text { Pressures } \\
\text { (mm.Hg) } \\
\text { PA } \quad \text { RV }\end{array}$}} & \multirow{2}{*}{$\begin{array}{l}\text { LV } \\
\text { or } \\
\text { Syst. }\end{array}$} & \multicolumn{4}{|c|}{ Oxygen Saturation } \\
\hline & & & & & & & & & split & single & & & & SVC & PA & RV & Syst. \\
\hline P.K. & M. & $6 \mathrm{yr}$. & $7 \mathrm{mth}$. & 3 mth. & $\begin{array}{l}\text { Dyspncea, } \\
\text { bronchitis, } \\
\text { congestive } \\
\text { failure, } \\
\text { feeding } \\
\text { difficulty }\end{array}$ & + & + & - & + & - & & & & & & & \\
\hline G.L. & $\mathbf{F}$ & $9 \mathrm{yr}$. & 9 mth. & 5 mth. & $\begin{array}{l}\text { Dyspncea, } \\
\text { congestive } \\
\text { failure, } \\
\text { feeding } \\
\text { difficulty }\end{array}$ & + & + & - & + & - & $60 / 20$ & $60 / 5$ & $90 / 30$ & 57 & 70 & 69 & - \\
\hline S.McD. & $\mathbf{F}$ & 8 yr. & $2 \mathrm{yr}$. & 2 mth. & $\begin{array}{l}\text { Dyspncea, } \\
\text { feeding } \\
\text { difficulty, } \\
\text { congestive } \\
\text { failure }\end{array}$ & + & - & - & + & - & $80 / 20$ & $85 / 7$ & $80 / 40$ & 50 & 84 & 86 & 96 \\
\hline R.P. & $\mathbf{M}$ & 6 mth.t & $6 \mathrm{mth}$. & $4 \mathrm{mth}$. & $\begin{array}{l}\text { Dyspnoea, } \\
\text { bronchitis, } \\
\text { congestive } \\
\text { failure, } \\
\text { cyanosis }\end{array}$ & + & - & + & + & - & $85 / 45$ & $85 / 0$ & $90 / 0$ & 60 & 80 & 80 & 82 \\
\hline J.G. & $\mathbf{F}$ & 5 yr. & $10 \mathrm{mth}$. & $4 \mathrm{mth}$. & $\begin{array}{l}\text { Bronchitis, } \\
\text { congestive } \\
\text { failure }\end{array}$ & + & + & - & + & - & & $70 / 6$ & Ir & compl & ete st & tudy & \\
\hline S.W. & $\mathbf{F}$ & 9 mth.t & 9 mth. & $6 \mathrm{mth}$. & $\begin{array}{l}\text { Congestive } \\
\text { failure, } \\
\text { feeding } \\
\text { difficulty, } \\
\text { cyanosis }\end{array}$ & + & - & + & - & + & $65 / 30$ & $65 / 15$ & $65 / 7$ & & & & \\
\hline J.B. & $\mathbf{M}$ & $7 \mathrm{yr}$. & 7 mth. & $2 \mathrm{mth}$ & $\begin{array}{l}\text { Feeding } \\
\text { difficulty, } \\
\text { cyanosis, } \\
\text { congestive } \\
\text { failure }\end{array}$ & + & + & - & + & - & & & & & & & \\
\hline S.B. & $\mathbf{F}$ & 2 mth.t & 2 mth. & Birth & $\begin{array}{l}\text { Dyspncea, } \\
\text { congestive } \\
\text { failure, } \\
\text { cyanosis }\end{array}$ & - & - & + & - & + & $85 / 30$ & $88 / 5$ & & 28 & 77 & 80 & 90 \\
\hline C.H. & $\mathbf{F}$ & $5 \mathrm{yr}$. & $10 \mathrm{mth}$. & $4 \mathrm{mth}$ & $\begin{array}{l}\text { Dyspncea, } \\
\text { feeding } \\
\text { difficulty, } \\
\text { congestive } \\
\text { failure }\end{array}$ & + & + & - & + & - & & $60 / 5$ & $60 / 30$ & 50 & & 92 & 92 \\
\hline K.F. & $\mathbf{M}$ & $\begin{array}{l}21 \\
\text { mth. }\end{array}$ & 4 mth. & $2 \mathrm{mth}$. & $\begin{array}{l}\text { Dyspncea, } \\
\text { feeding } \\
\text { difficulty, } \\
\text { congestive } \\
\text { failure }\end{array}$ & + & + & - & + & - & $78 / 20$ & $80 / 0$ & $75 / 30$ & 27 & 78 & 77 & 93 \\
\hline C.F. & $\mathbf{F}$ & 9 yr. & 5 mth. & 3 wk. & $\begin{array}{l}\text { Dyspncea, } \\
\text { bronchitis, } \\
\text { congestive } \\
\text { failure }\end{array}$ & + & + & - & + & - & & & & & & & \\
\hline A.C. & $\mathbf{F}$ & 6 wk.t & 2 mth. & 2 wk. & $\begin{array}{l}\text { Dyspncea, } \\
\text { cyanosis, } \\
\text { congestive } \\
\text { failure }\end{array}$ & + & - & - & - & + & Ventri & sular fibr & llation $\mathrm{u}$ & vith loc & al an & læsth & Lesia \\
\hline
\end{tabular}

* Age at death or when last seen alive.

† Dead.

tricular septal defect with loud systolic and delayed diastolic murmurs and close splitting of the second sound. In 3 patients, auscultation suggested important pulmonary vascular disease owing to the presence of loud ejection click, ringing single second sound, and less impressive parasternal murmurs.

The electrocardiogram was typical of atrioventricular defects in 11 patients with a mean frontal axis between $-60^{\circ}$ and $-120^{\circ}$ (Fig. 1a). One patient in whom the diagnosis was confirmed at necropsy had an axis of $+90^{\circ}$ (Fig. 1b). The P-R interval was prolonged for rate in 7 patients, and there was evidence of right atrial hypertrophy with $P$ exceeding $3 \mathrm{~mm}$. in 8 . All patients had right ventricular hypertrophy with high voltage in V1 and V4R. This was severe with steeply inverted $T$ waves in 9; 4 had right bundle-branch block. Associated left ventricular hypertrophy with large $\mathrm{qR}$ patterns in V5, V7, and VL, was present in 2 patients; large equiphasic complexes were noted in anterior chest leads in 9 patients.

Gross cardiomegaly was constantly found on the chest radiograph with cardiothoracic ratios exceeding 60 per cent (Fig. 2a). Dilatation involved all 

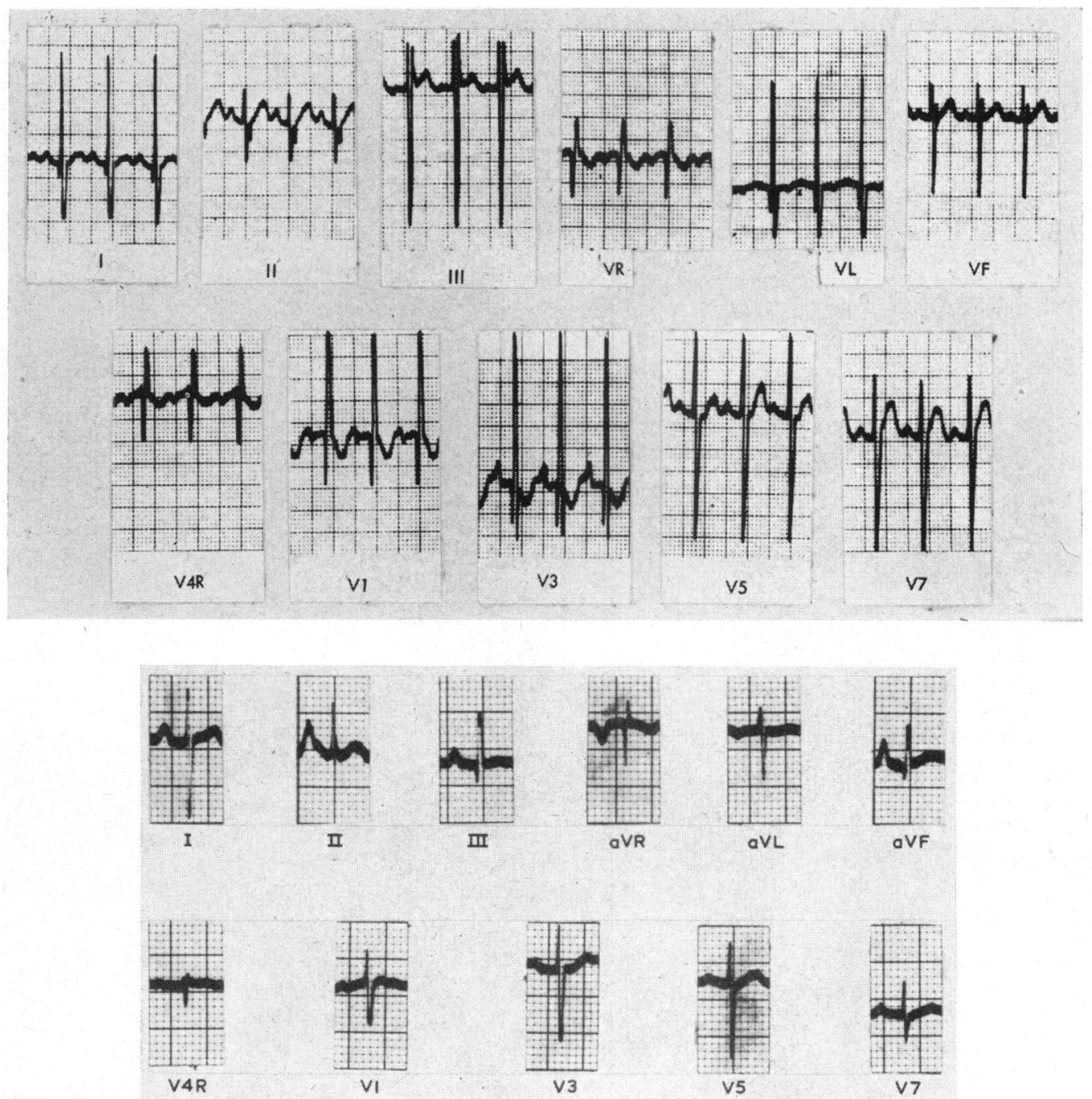

Fig. 1.-Pre-operative electrocardiograms from two patients with common atrioventricular canal. (Above) Typical electrocardiogram showing left axis deviation found in 11 patients; from S.McD., aged 8 months. (Below) Atypical electrocardiogram showing right axis deviation; from S.W., aged 9 months.

chambers, with particular prominence of the right atrium. The pulmonary artery segment was large and the lung vascularity appeared to be increased in all except one patient (S.W.). Anterior bulging of the sternum with indrawing at the diaphragmatic attachment was seen on the lateral chest plate (Fig. $2 \mathrm{~b}$ ), corresponding to the symmetrically bulged chest with indrawn lower ribs clinically evident in 11 patients.

Pre-operative cardiac catheterization was done in 7 patients. One child had a right ventricular angiogram only, and in another, catheterization was abandoned following a cardiac arrest from which the infant was successfully resuscitated. Three severely ill patients did not have hæmodynamic studies before banding. The results of pre-operative investigations are shown in Table I. A left-to-right shunt which showed at atrial level was found in each patient; this was small in two and larger, approximately 3 to 1 , in the other five. A right-to-left shunt was clear in two patients (R.P. and S.B.) and probable in two others (C.H. and K.F.). Ventricular pressures were balanced in 6 and the atrial septum was crossed in all. In 4 patients, the mean left atrial pressure exceeded the right by $2-5 \mathrm{~mm}$., suggesting that the atrial component was small or 

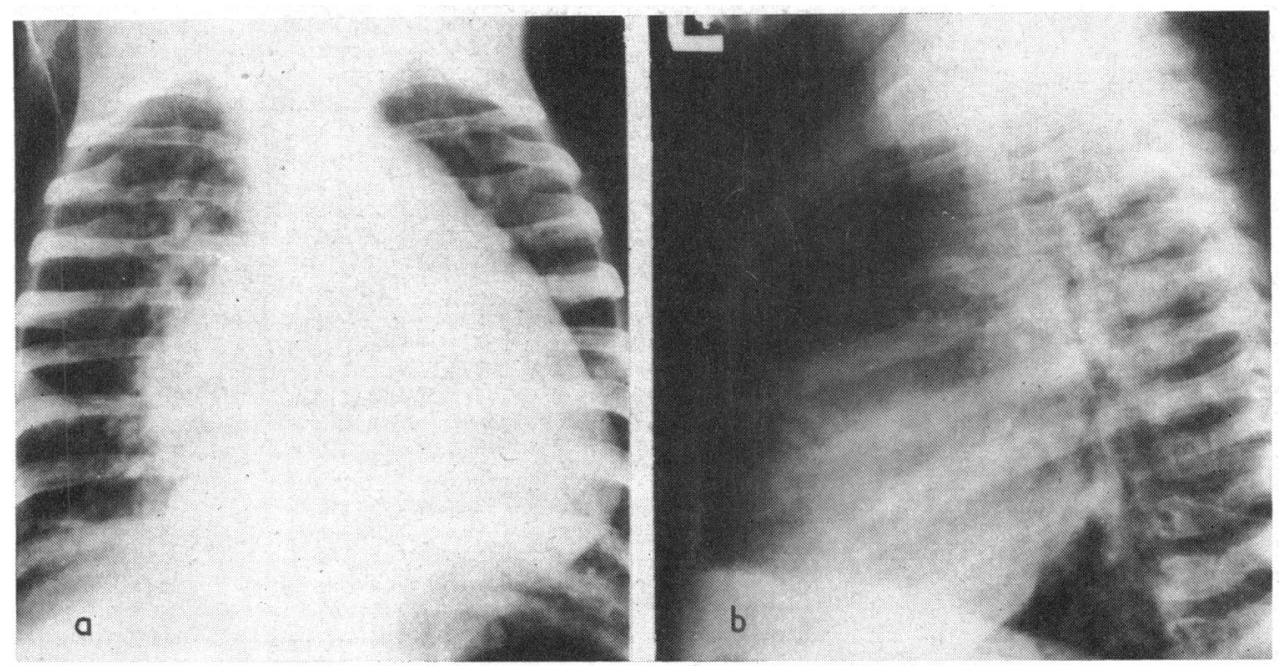

FIG. 2.- Chest radiographs of patient K.F. three days before banding. (a) Antero-posterior view showing gross cardiomegaly and pulmonary plethora. (b) Lateral view showing anteriorly bulged chest and large heart.

that mitral regurgitation was important, or a combination of both factors.

Banding Procedure. The operations were done through a left thoracotomy (by D.J.W. or E.A.). The ductus or ligamentum was dissected and ligated in all cases. The main pulmonary artery was exposed, and a ligature of plaited silk was tied around it just above the pulmonary valves and tightened until the lumen of the vessel was reduced to one third of its original diameter. The aim was to reduce the distal pulmonary artery pressure to near normal and to create a gradient of $30 \mathrm{~mm} . \mathrm{Hg}$ or more across the band. The changes in pressure produced at the time of banding have been shown (Fig. 3). The smallest gradient made was $8 \mathrm{~mm} . \mathrm{Hg}$, because further tightening of the band in this patient (R.P.) caused acute right ventricular dilatation and ventricular fibrillation; the patient died one day later and was shown to have histological evidence of severe pulmonary vascular disease. After application of the band in the remaining 11 patients, the right ventri-
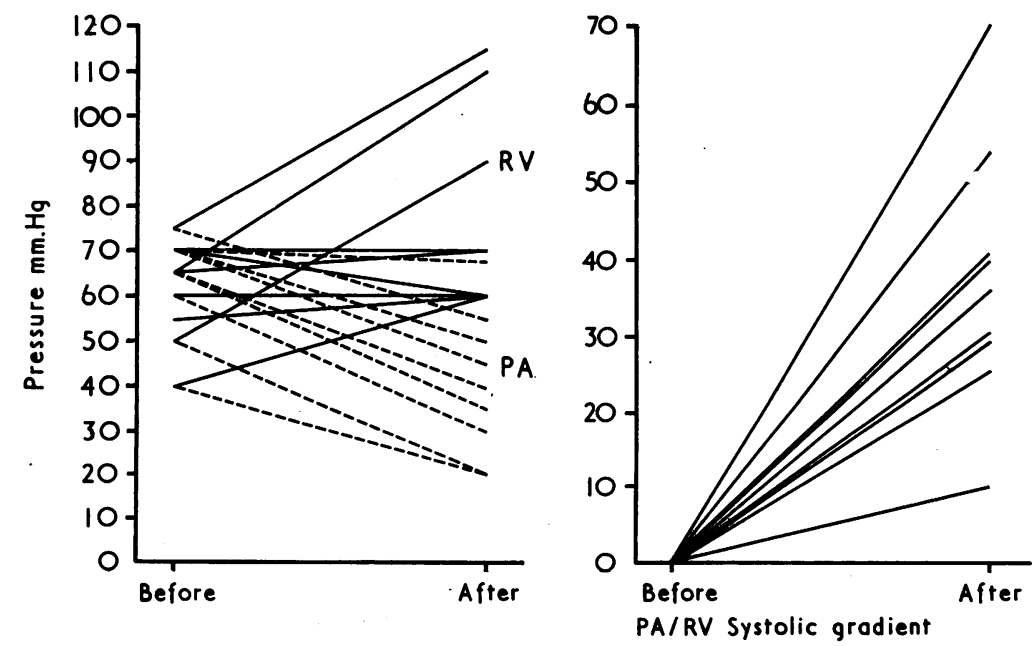

FIG. 3.-Pressure changes before and after banding recorded at the time of operation. (Left) Change in right ventricular and pulmonary artery systolic pressures. (Right) Change in peak systolic gradient. 
TABLE. II

FINDINGS IN PATIENTS WHO DIED AFTER BANDING

\begin{tabular}{|c|c|c|c|c|c|}
\hline Patient & $\begin{array}{l}\text { Age } \\
\text { at banding } \\
\text { (mth.) }\end{array}$ & Atrioventricular defect & Additional lesions & A-V valve & $\begin{array}{c}\text { Severity of } \\
\text { pulmonary vascular }_{\text {disease }}^{\star}\end{array}$ \\
\hline R.P. & 6 & $\begin{array}{l}3 \mathrm{~cm} . \text { A-V canal; } \\
\text { Large VSD }\end{array}$ & $1 \mathrm{~cm}$. secundum ASD & $\begin{array}{l}\text { Cleft mitral; } \\
\text { cusps well formed }\end{array}$ & Severe \\
\hline S.W. & 9 & $3 \mathrm{~cm}$. A-V canal & Small secundum defect & $\begin{array}{l}\text { Poorly formed } \\
\text { deficient cusps }\end{array}$ & Severe \\
\hline S.B. & 2 & $2 \mathrm{~cm}$. A-V canal & $\begin{array}{l}0.5 \mathrm{~cm} \text {. VSD; } \\
\text { hypoplastic aortic arch; } \\
\text { coarctation;PDA; hemi- } \\
\text { anomalous pulm. veins } \rightarrow \text { R.A. }\end{array}$ & $\begin{array}{l}\text { Poorly formed } \\
\text { deficient cusps }\end{array}$ & Severe \\
\hline K.F.t & 4 & $\begin{array}{l}\text { Atrial component } 1 \mathrm{~cm} . ; \\
\text { VSD } 2.5 \mathrm{~cm} .\end{array}$ & - & No comment & Mild \\
\hline A.C. & 2 & $3 \mathrm{~cm}$. A-V canal & Large secundum ASD & $\begin{array}{l}\text { Poorly formed } \\
\text { deficient cusps }\end{array}$ & Severe \\
\hline
\end{tabular}

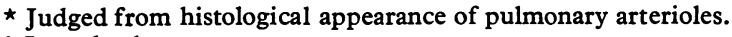

t Late death.

cular pressure rose after several beats and then the pulmonary artery pressure fell.

Results of Banding. The age of the patients at the time of operation and those who died have been indicated (Table I). One patient (A.C.) had two cardiac arrests before operation. There were 4 operative deaths and 1 late death 18 months after operation. This child (K.F.) was initially improved and digitalis was stopped after one year; six months later, the child suddenly became pale and ill and died an hour later. It was concluded that an arrhythmia had caused this deterioration.

The anatomical diagnosis in the patients who died was confirmed at necropsy (Table II). Severe pulmonary arteriolar disease was found in each of the 4 patients who died at operation but important additional lesions were found in only one patient (S.B.). In 3 patients, common atrioventricular valve was poorly formed with deficient cusps and assumed to be grossly incompetent. In the other 2, the cusps were more voluminous and better shaped, suggesting two valve mechanisms rather than a grossly incompetent single valve. The 7 surviving children have now been followed for 4-9 years. The initial post-operative improvement was slow in 6 , and right heart failure persisted for at least a year in all except 1 (C.F.). Digitalis and diuretics were needed during the first year and were then discontinued, but in 3 digitalis was required again. One patient (C.H.) developed severe cardiac failure at the age of 3 years. During this time her electrocardiogram showed that transient left bundle-branch block had developed; this reverted after three weeks and there was a corresponding improvement in her clinical state. It is probable that this change occurred as a result of an arrhythmia but this was not certain from the electrocardiogram (Fig. 4). Some effort dyspnœa was present in all; this was mild in 4 and moderate in 3. All children managed normal schooling.

Post-operative Data. Clinical Examination. The jugular venous pulsations were exaggerated with prominent $\mathrm{A}$ waves in all. Increase of pressure suggesting failure was noted at the last examination in 2 patients (J.B. and J.G.). Clubbing of the fingers was present in 3 (C.H., S.McD., J.G.) and all patients were cyanosed after effort though this was not always apparent at rest. The right ventricle felt powerful and dilated. It was difficult at the bedside to distinguish separate left ventricular hypertrophy from the character of the apex beat. In each patient, there was a long ejection murmur associated with a thrill, heard best in the pulmonary area and widely conducted down the left sternal edge towards the apex. An ejection click was present in 4 patients. Pulmonary valve closure was accentuated and delayed in 6 patients (Fig. 5). A separate pansystolic murmur of mitral incompetence was present at the apex in 4 children but required phonocardiographic confirmation owing to the difficulties of identifying mitral regurgitation in the presence of pulmonary stenosis (Somerville, 1966a). A third heart sound was recorded in 4 patients.

Electrocardiogram. Right ventricular hypertrophy increased in the 7 surviving children as shown by increasing voltage of QRS and ST depression 
14.1.63. AGE 2 years
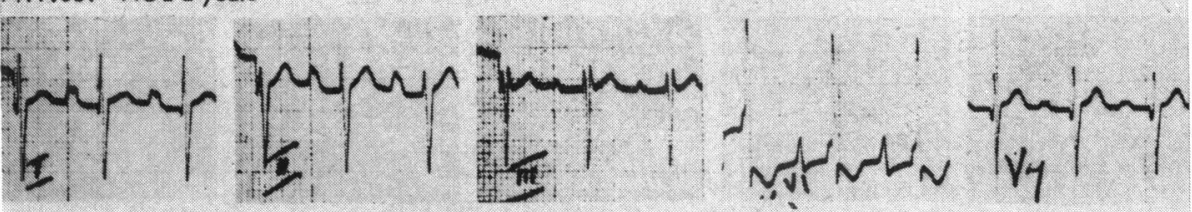

23.6.64. AGE $3^{1 / 2}$ years
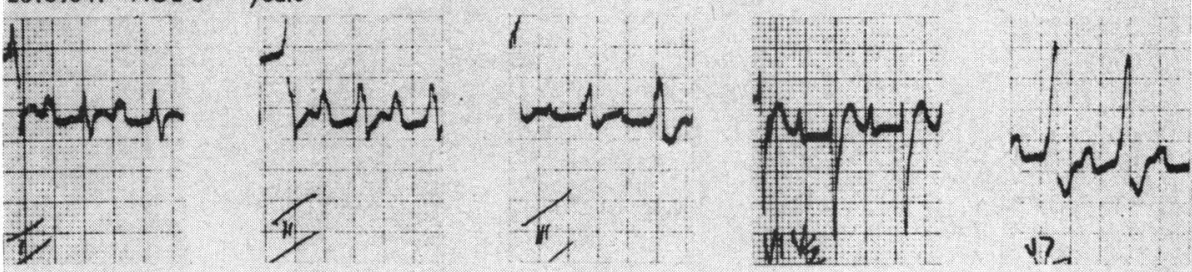

17.
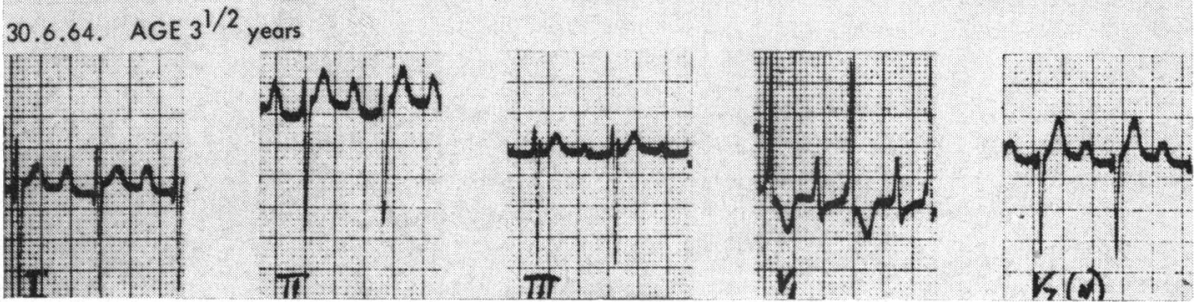

FIG. 4.-Changing electrical axis associated with alteration of bundle-branch block pattern and deterioration in patient's (C.H.) physical state.

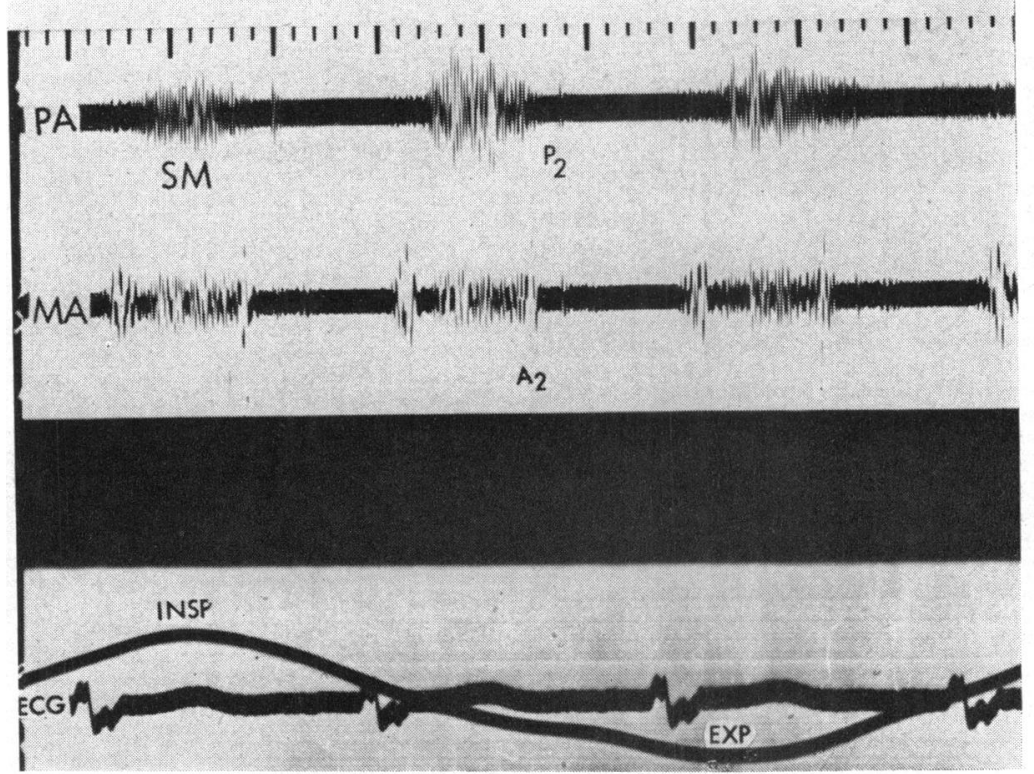

Fig. 5.-External phonocardiogram showing delayed pulmonary valve closure $\left(P_{2}\right) 0.08$ sec. after aortic valve closure $\left(\mathrm{A}_{2}\right), 6$ years after banding of the pulmonary artery. From patient S.Mc.D. aged $6 \frac{1}{2}$ years. $\mathrm{PA}=$ Pulmonary area; $\mathrm{MA}=$ Mitral area $\mathbf{S M}=$ Systolic ejection murmur; INSP = Inspiration; $\mathrm{A}_{2}=$ Aortic valve closure; $P_{2}=$ Pulmonary valve closure. 


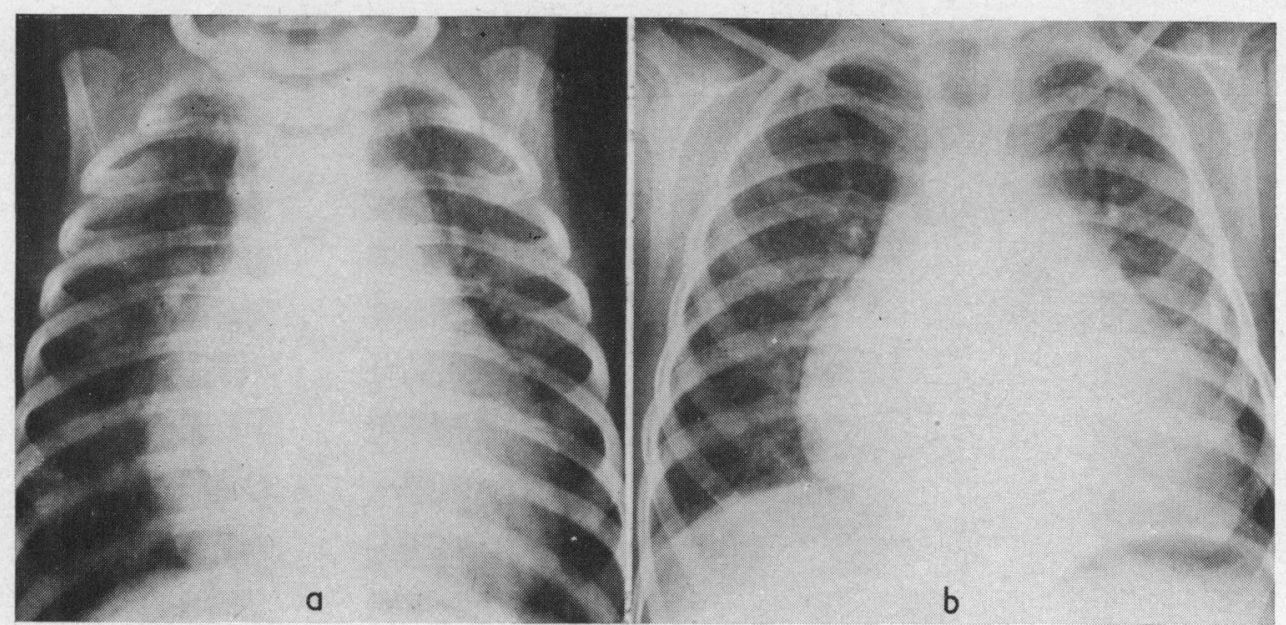

FIG. 6.-Chest radiographs showing persistent cardiomegaly after banding in patient J.B. (a) Before banding, age 3 months. (B) Four years after banding.

with steeper $\mathbf{T}$ inversion in the right præcordial leads. There was a marked increase in the size of the $P$ wave in V1 in all except one patient (C.F.). The $S$ waves in the right chest leads diminished and increased in the left chest leads, and $R$ waves in V567 diminished in 3, suggesting decrease in size of the left ventricle.

Chest Radiograph. The heart remained large in 5 patients following banding (Fig. 6), even though there was clinical improvement in all. Persistent cardiac enlargement was due to dilatation of the right atrium and right ventricle. The proximal pulmonary artery segment was prominent in 6 , and lung fields were slightly plethoric in 3 , underfilled in 2 , and normal in 2 . In 2 patients, the heart size became normal (Fig. 7). Left atrial enlargement, as judged by splaying of the carina, was present in 5 patients but was not apparent in two patients (P.W. and C.H.) who had no evidence of important mitral regurgitation. The lateral chest radiographs confirmed the change in chest shape that was noted clinically in 6 of 7 survivors (Fig. 8). This was also obvious from examination in patient K.F. one year after banding.

Post-operative Investigation. Post-operative cardiac catheterization was performed in 6 patients.
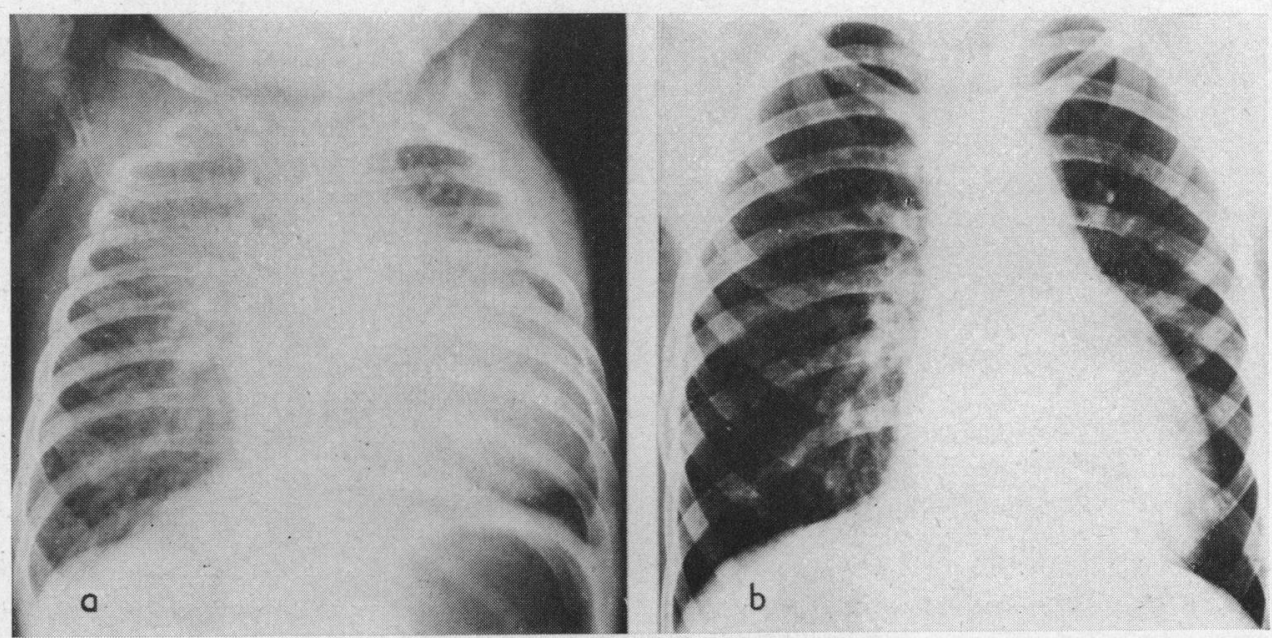

FIG. 7.-Chest radiographs showing diminution in heart size following banding in patient C.F. (a) Before banding. (b) Eight years after banding. 
TABLE III

POST-OPERATIVE CARDIAC CATHETERIZATION

\begin{tabular}{|c|c|c|c|c|c|c|c|c|c|c|}
\hline \multirow{2}{*}{ Patient } & \multicolumn{6}{|c|}{ Pressure data (mm.Hg) } & \multicolumn{3}{|c|}{$\underset{(\%)}{\text { Oxygen saturation data }}$} & \multirow{2}{*}{ Angiography } \\
\hline & PA (distal) & PA (prox.) & RV & RA & LA & LV & Aorta & PA \% & Shunt & \\
\hline P.K. & $40 / 15$ & $95 / 20$ & $95 / 2-10$ & 4 & $\begin{array}{c}a=12 \\
v=8\end{array}$ & $80 / 5-15$ & 86 & 81 & $\underset{\mathrm{L} \rightarrow \mathrm{R}}{\text { Domi- }}$ & $\begin{array}{l}\text { Two atrial defects; mild mitral } \\
\text { regurgitation; moderate } \\
\text { VSD }\end{array}$ \\
\hline S.McD. & $45 / 30$ & $95 / 50$ & $100 / 0$ & 4 & $\begin{array}{c}10 \\
v=15\end{array}$ & $100 / 0$ & 92 & 82 & $\underset{\substack{\text { Domi- } \\
\mathrm{L} \rightarrow \mathbf{R}}}{\underset{1}{\text { Dont }}}$ & $\begin{array}{l}\text { Single atrial defect; moderate } \\
\text { mitral regurgitation directed } \\
\text { towards RA; moderate VSD }\end{array}$ \\
\hline J.G. & $\begin{array}{c}\text { Wedge PCV } \\
\text { Mean } 15\end{array}$ & $95 / 5$ & $95 / 0$ & 3 & 4 & $95 / 0$ & 81 & 75 & $\underset{\mathbf{L} \rightarrow \mathbf{R}}{\text { Domi- }}$ & $\begin{array}{l}\text { Very large atrial component: } \\
\text { dilated LV; gross } M I \text {; } \\
\text { anatomy of septum obscured } \\
\text { by regurgitant jet; } \\
\text { ?small VSD }\end{array}$ \\
\hline J.B. & - & $95 / 12$ & $95 / 0$ & 3 & 3 & $95 / 0$ & 93 & 75 & $\underset{\mathbf{L} \rightarrow \mathbf{R}}{\text { Domi- }}$ & $\begin{array}{l}\text { Small ASD; deformed mitral } \\
\text { valve; minimal MI; } \\
\text { moderate VSD }\end{array}$ \\
\hline C.H. & $24 / 8$ & $95 / 10$ & $95 / 0-6$ & $v=10$ & $v \stackrel{10}{=15}$ & $100 / 0-6$ & 81 & 78 & $\underset{\substack{\text { nant } \\
L \rightarrow R}}{\text { Domi- }}$ & $\begin{array}{l}\text { Large ASD; deformed } \\
\text { mitral valve; severe } \mathrm{MI} \text {; } \\
\text { moderate VSD }\end{array}$ \\
\hline C.F. & $\begin{array}{c}\text { Wedge PCV } \\
50 / 25\end{array}$ & & $110 / 5$ & $v \stackrel{5}{=10}$ & $\begin{array}{c}7 \\
a=13 \\
v=13\end{array}$ & $110 / 5$ & 91 & $\begin{array}{r}\text { RV } \\
75\end{array}$ & $\begin{array}{r}\text { Bidirec- } \\
\text { tional }\end{array}$ & $\begin{array}{l}\text { Small ASD; deformed mitral } \\
\text { valve; little MI; large } \\
\text { ventricular component and } \\
\text { additional small muscular } \\
\text { VSD }\end{array}$ \\
\hline
\end{tabular}

One patient (S.B.) who was mentally retarded was not restudied but had an excellent clinical result. Ventricular pressures were balanced in all except one patient (J.G.) in whom the right ventricular pressure exceeded the left by $15 \mathrm{~mm} . \mathrm{Hg}$. In the patients with balanced resting pressures, the right ventricular and aortic pressures remained the same under changing conditions, supporting the view that the ventricular component of the defect was large. It was difficult to pass the catheters across the band, and the distal pulmonary artery pressure could not be measured in 2 patients. Results of post-operative studies have been shown (Table III). In 3 patients, the distal pulmonary artery pressure was raised with peak systolic levels between 40-50 $\mathrm{mm} . \mathrm{Hg}$, and in 2 it was normal. The pressure wave in the proximal pulmonary artery segment had a similar wave form to the one in the right ventricle,
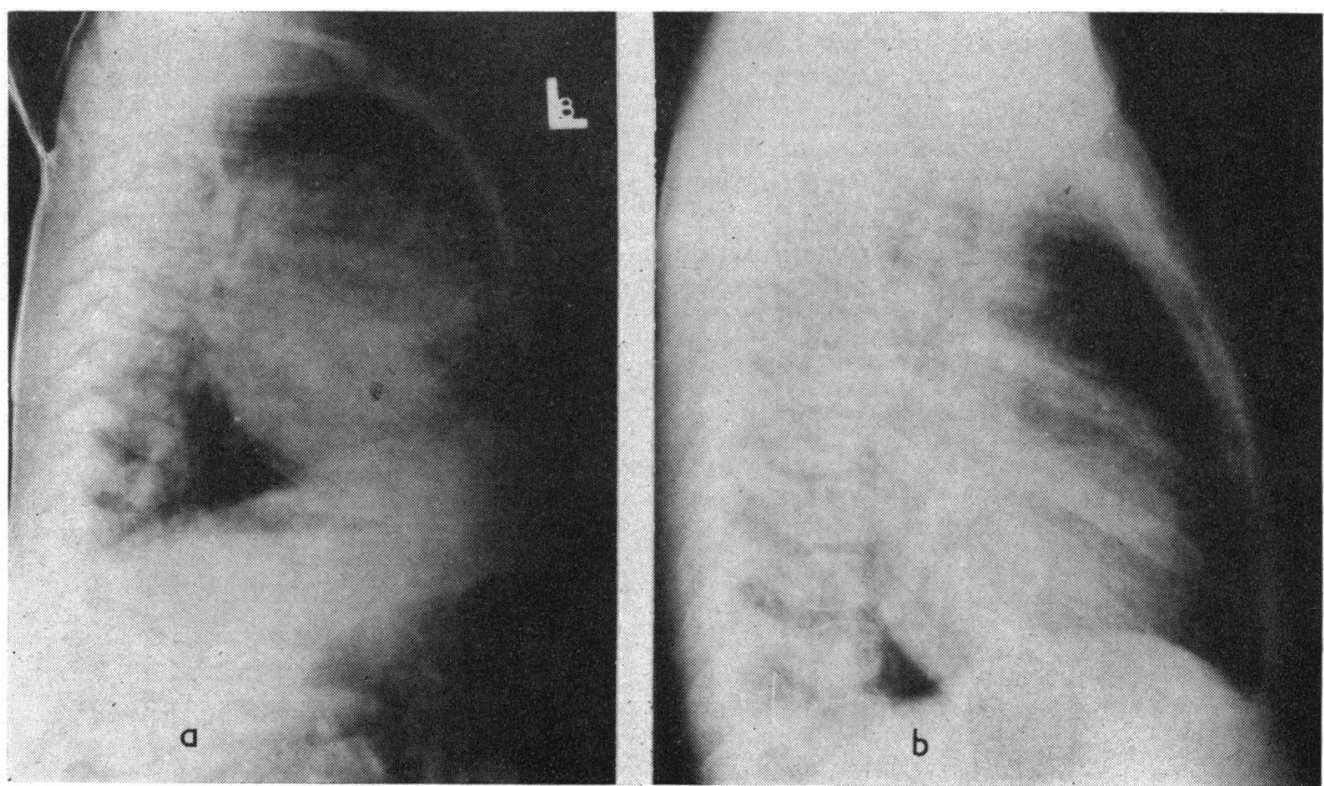

FIG. 8.-Lateral chest radiographs showing change in chest shape following banding in patient J.B. (a) One day before banding, at age 7 months. (b) Three years after banding. 


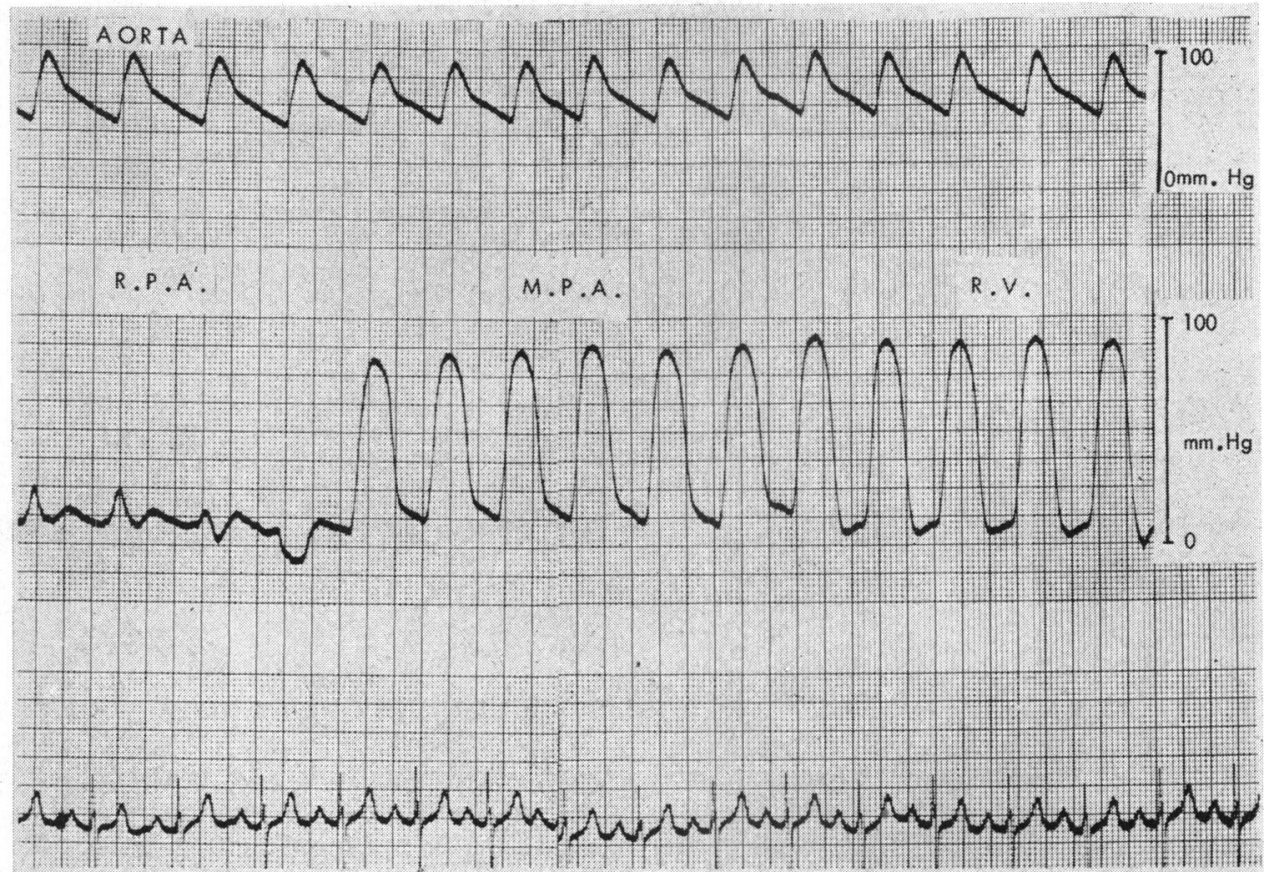

FIG. 9.-Pressure withdrawal tracing across the banded pulmonary artery from patient C.H. (Tracing cut and rejoined in middle of M.P.A. to limit length for reproduction.)

with a higher diastolic pressure, of between 5-15 mm.Hg (Fig. 9). The atrial septum was easily crossed in all patients. Left and right atrial pressures were similar in 3 patients and usually normal at the time of catheterization. The wave form of left atrial pressure records was significantly abnormal with large "v" waves of approximately 11 $\mathrm{mm}$., and suggested mitral regurgitation in 3 patients. The left atrial pressure was found to be an unreliable guide to the severity of the mitral regurgitation in this condition. Oxygen saturation figures showed the presence of bidirectional shunts in 5 patients and in one it was only left to right. The resting systemic arterial oxygen saturation varied between 81 and 93 per cent.

Right ventricular angiography was undertaken to show the site of the band as well as the anatomy of the ventricular septal defect. In 5 patients the band was close to the bifurcation of the main pulmonary artery (Fig. 10a). The size of the proximal pulmonary artery segment changed considerably during the cardiac cycle and was maximal in mid to late systole.

Left ventricular angiography confirmed the presence of the ventricular component of the atrioventricular defect, and in two suggested that there was an additional defect in the muscular septum near the apex corresponding to an interventricular shunt shown by right ventricular angiography (Fig. 10a and $b$ ). The typical deformity of the left ventriular outflow tract due to abnormal attachment of the mitral valve was present in all the cases investigated (Fig. 11). It was difficult to quantitate mitral regurgitation since the catheter had been passed into the left ventricle through the mitral valve in 3 ; in the others it was passed through the ventricular septal defect or retrogradely through the aortic valve. The jet of mitral regurgitation was directed mainly towards the right atrium and was small or slight in 3 and large, representing moderate or severe regurgitation, in the other 3 patients.

Left atrial angiography was performed in 5 patients in order to outline the anatomy and size of the atrial septal defect. The contrast medium passed from left to right atrium low in the atrial septum, confirming the presence of an ostium primum defect (Fig. 12). The defect appeared to occupy at least one-third of the atrial septum in 4 patients and looked smaller in C.F. In 2 patients, a left-to-right shunt occurred higher in the atrial septum, suggesting the presence of an additional secundum defect in the region of the fossa ovalis.

\section{Discussion}

The operative mortality of banding in infants with common atrioventricular canal in the current series 

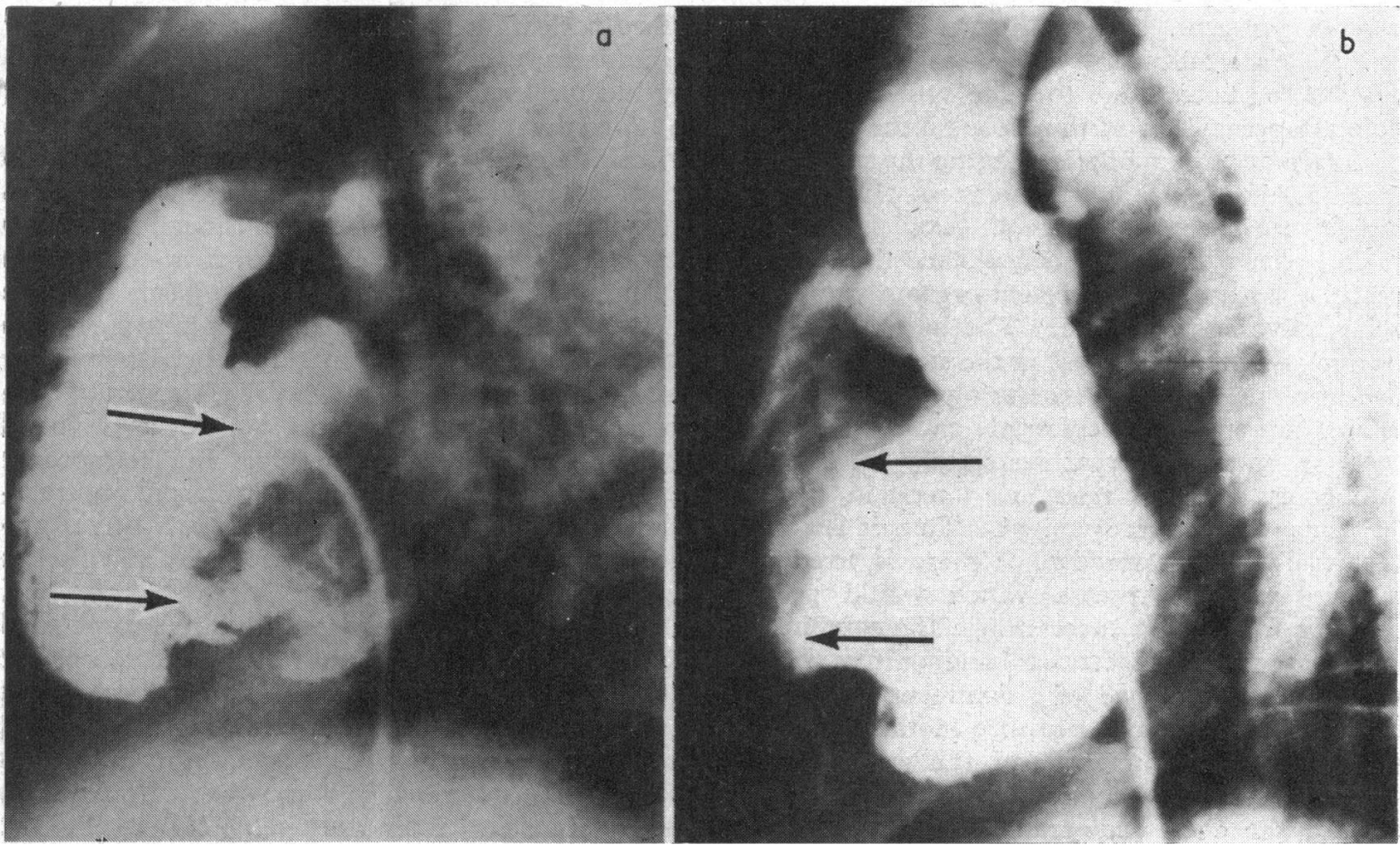

Fig. 10.-Lateral views of ventricular angiocardiograms showing defects in the muscular (lower-arrows) and membranous (upper arrows) ventricular septum. (a) Right ventricular angiocardiogram. (b) Left ventricular angiocardiogram.

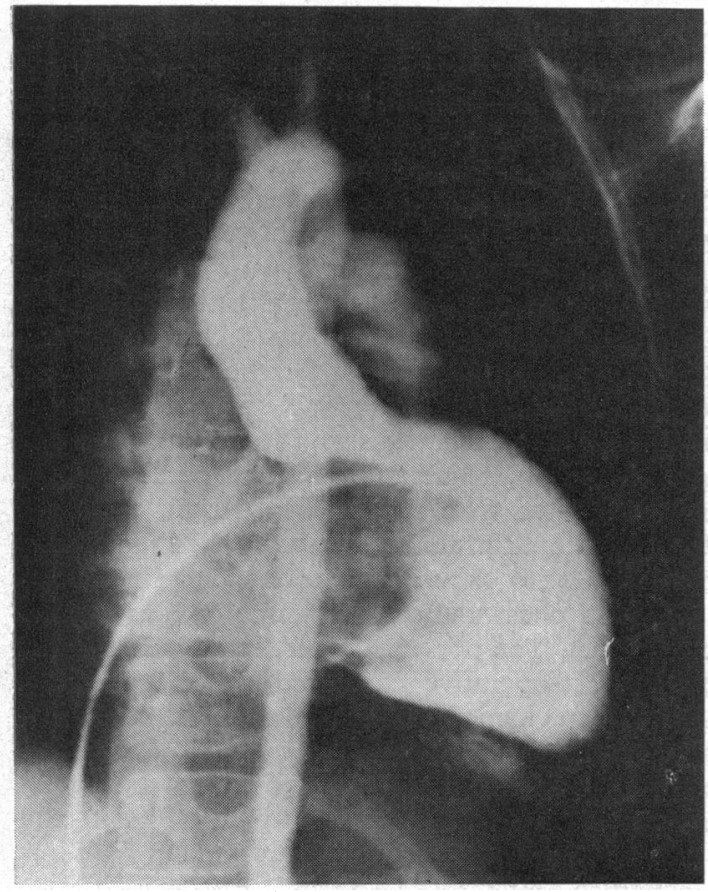

FIG. 11.-Antero-posterior view of left ventricular angiocardiogram showing typically deformed outflow of the left ventricle due to abnormal attachment of the mitral valve. (From patient P.K.)

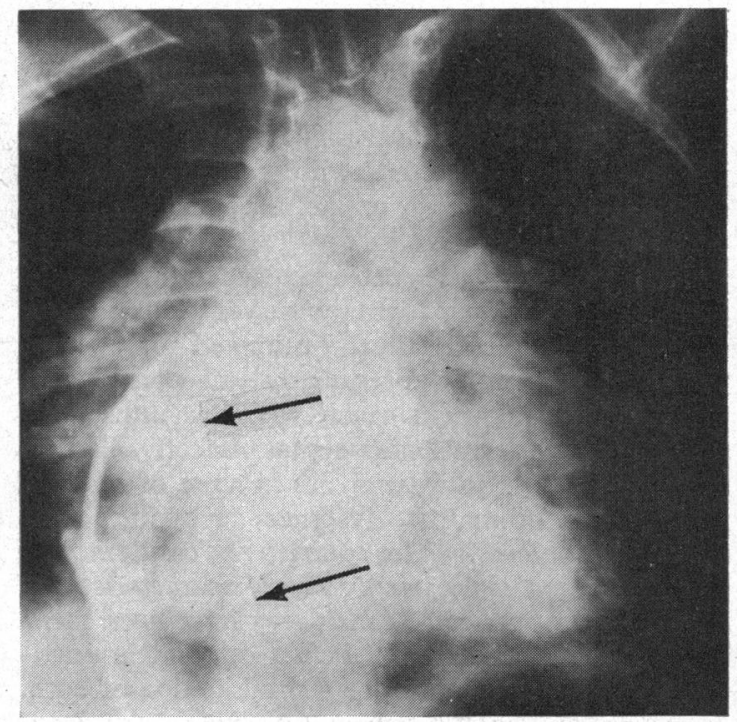

FIG. 12.-Left atrial angiocardiogram showing contrast medium passing into right atrium through ostium primum defect (lower arrow) and across separate fossa ovalis defect (upper arrow). (From Patient J.G.) 
was 33 per cent. This contrasts with the lower operative mortality of 2.3 per cent in 41 infants banded for failure due to large ventricular septal defects operated on at the Hospital for Sick Children (Great Ormond Street) during the same period (Stark, Aberdeen, and Waterston, 1967). The higher mortality in common canal is probably related to two factors, namely advanced pulmonary vascular disease and important organic atrioventricular valve regurgitation. The severity of both factors is difficult to assess in the sick infant before banding. Methods of measuring shunts in these infants are still relatively crude and the effects of sedation and concurrent respiratory infection on pulmonary arteriolar resistance uncertain, particularly where it is already raised. Thus it is hard to predict from catheter data if there is fixed pulmonary vascular disease which would prevent banding from being successful. The combination of features which suggest that banding may not succeed are the presence of a dominant right-to-left shunt, a high diastolic pressure in the pulmonary artery above $35 \mathrm{~mm} . \mathrm{Hg}$, and the appearance of normal or only slightly increased pulmonary blood flow in the chest radiograph, as in patient S.W. Unless there is no evidence of a left-to-right shunt, the risk of banding is considered justifiable in infants under 1 year with common atrioventricular canal and chronic failure in view of the high medical mortality at this stage of the disease.

The severity and importance of mitral regurgitation in the infant with common canal is also difficult to assess before banding. Necropsy findings in 3 of the 4 operative deaths showed severe disorganization of the common atrioventricular valve which must have been grossly incompetent. Of the survivors, 3 were shown by post-operative investigation to have severe mitral regurgitation and in the other 3 it was trivial. It seems likely, then, that the outcome of banding may in part depend on the function of the mitral valve.

In the survivors, the post-operative course differed from that found in patients with ventricular septal defect. Right heart failure prolonged for up to a year and recurring subsequently was common in patients with common canal, which is unusual in uncomplicated ventricular septal defect. Cardiomegaly persisted in 6 survivors in spite of relief of troublesome bronchitis, dyspnœa, tachypnœa, and feeding problems. The persistent cardiomegaly and prolonged right heart failure, characteristic of banded atrioventricular canal, may have been attributable to an atrial septal defect or to atrioventricular valve regurgitation, or a combination of both. In view of the small number of patients, it has been difficult to separate the role of these two factors.
Two patients with trivial mitral regurgitation had uneventful post-operative courses and encouraging reduction in heart size; left atrial angiography showed that one of them had a small and the other a sizeable atrial septal defect. The atrial defect alone does not seem to be responsible for the post-operative problems in these patients, though when large enough to permit equalization or near equalization of atrial pressures, it may be at least partly to blame. Mitral regurgitation may then transmit a pressure wave to the right heart, resulting in persistent failure and cardiomegaly. It is thus likely that the combination of these two factors causes the persistent heart failure and cardiomegaly. Furthermore, in common atrioventricular canal, tricuspid regurgitation through an abnormal tricuspid valve in the presence of right ventricular hypertension may further embarrass the right ventricle.

The presence of the band gives rise to physical signs of pulmonary stenosis which were recognized in the children over 2 years. The ejection murmur was long but did not spill over aortic valve closure, and in no instance was a continuous murmur present as has been described in some cases of pulmonary artery stenosis. Pulmonary valve closure $\left(\mathrm{P}_{2}\right)$ was delayed in all the patients: this was unexpected in view of the large ventricular component of the defect demonstrated in 5 of the 6 patients who were investigated. Delayed pulmonary valve closure was attributed to prolonged ejection of the hypertrophied and overloaded right ventricle. An immediate diastolic murmur probably due to pulmonary regurgitation was present in 2 patients who had the largest proximal main pulmonary arteries found in the series. Central cyanosis was more marked in patients banded for common canal than in those with ventricular septal defect and was confirmed by measurement of systemic arterial saturations (Fig. 13). This could not be explained entirely by the tightness of the band, for it has been noted when relatively mild pulmonary valve stenosis complicates atrioventricular defects (Somerville, 1966b). In view of this finding and the post-operative problems associated with an overloaded right ventricle, the band should probably not be applied too tightly in patients with common atrioventricular canal.

Routine chest radiography provided useful information. The presence of left atrial enlargement in the post-operative chest radiograph correlated with other evidence of important mitral regurgitation. The loss of the anterior bulging of the chest wall noted clinically and confirmed on the lateral radiograph in 5 patients was striking (Fig. 8) and has also been observed in infants banded for large ventricular septal defect and in infants where large ducts carrying high flows have been occluded. 


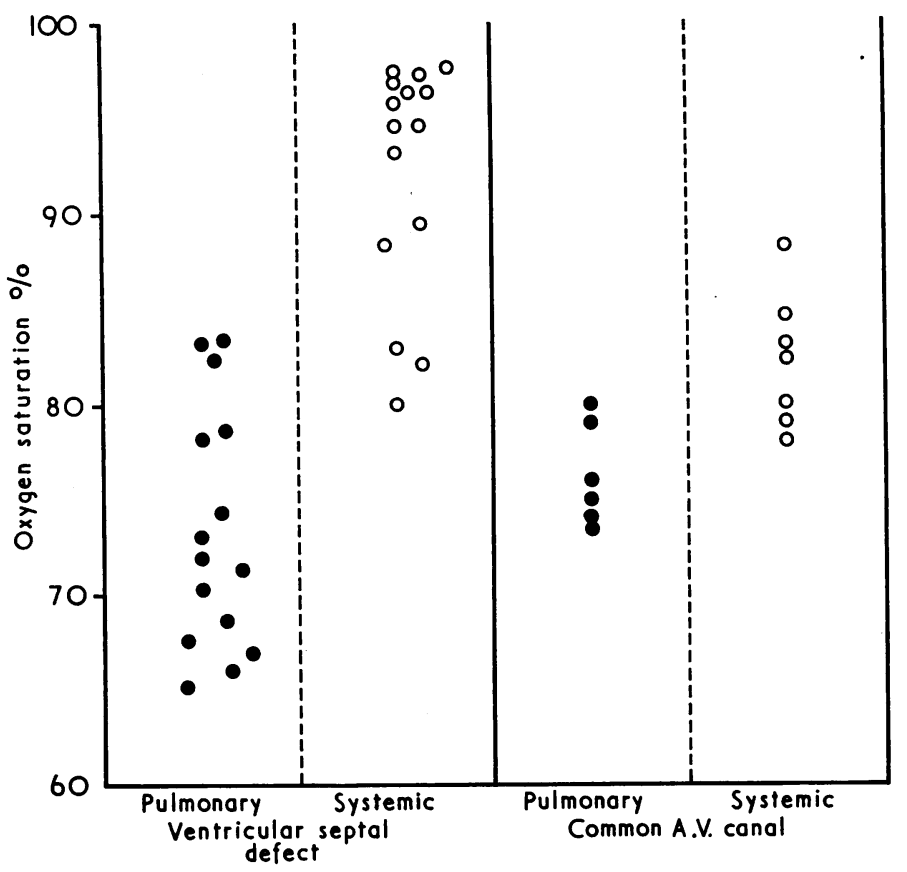

FIG. 13.-Oxygen saturations in pulmonary and systemic arteries in patients previously banded for uncomplicated ventricular septal defect and common atrioventricular canal.

These observations suggest that banding of the pulmonary artery, which reduces the distal pulmonary artery pressure and blood flow, may increase the lung compliance and make breathing easier, resulting in the disappearance of the chest distension. Older patients with hyperkinetic pulmonary hypertension associated with common atrioventricular canal or ventricular septal defect characteristically have bulged chests (Davies, 1959) and the lung compliance has been found to be reduced in such patients (Davies, Williams, and Wood, 1962). Unfortunately, no measurements of lung compliance were made in the current series of infants, but if this postulate is true it is probable that the therapeutic benefits from banding result from the alteration in lung compliance as well as the diminishing distal pulmonary hypertension which leads to regression of pulmonary vascular changes (Dammann et al., 1961).

It may be difficult to differentiate between patients with common atrioventricular canal and those with separate atrial and ventricular septal defects or ventricular septal defects and tricuspid regurgitation. Left axis deviation with $S_{2} S_{3}$ pattern, together with right bundle-branch block and biventricular hypertrophy, may be found in any of these conditions though it is more frequent with common atrioventricular canal. The association of prolongation of the P-R interval with this typical electrocardiogram is strongly suggestive of an atrioventricular defect. However, the only certain method of separating these conditions is by using left ventricular angiocardiography which has been found always to be reliable '(Somerville and Jefferson, 1967). Before removal of the band and repair of the central defect, right and left ventricular angiocardiography are considered to be obligatory in order to delineate the anatomy of the septal defect and atrioventricular valves.

Other forms of atrioventricular defect such as the ostium primum with no functioning ventricular component of the defect and single atrium do not usually present in infancy with resistant heart failure unless there are important additional lesions in the cardiovascular system. It is not possible to differentiate the type of atrioventricular defect in infants without angiography, but if the patient presents early it may be assumed that the lesion is a common canal, provided there are no additional complications. Post-operative investigation in this series has confirmed the diagnosis of common atrioventricular canal by the demonstration of a ventricular septal defect beneath the atrioventricular valves. The pathological anatomy and clinical function 
vary widely in patients with common canal, but it appears that those patients with a large ventricular component of the defect and only trivial mitral regurgitation will derive nost benefit from banding of the pulmonary artery.

At the present time, none of the patients who survived banding for common atrioventricular canal have had repair of the atrioventricular defect and removal of the band. Since the presence of the band must add a considerable load on the right ventricle, radical corrective surgery should ideally be done as soon as the child has reached an age and size that allow easy perfusion. Experience with banded ventricular septal defects has shown that the problems of removing the band are not difficult but unfortunately the risks of repair of common atrioventricular canal are still high. Although banding has probably removed the post-operative disasters related to pulmonary hypertension and vascular disease, the problems of repair of the badly deformed mitral valve have yet to be satisfactorily solved. It is likely that banding in the survivors was life-saving, and it is hoped that the problems of total correction of common atrioventricular canal will soon be overcome.

\section{SUMMARY}

Banding of the pulmonary artery for common atrioventricular canal was performed in 12 infants aged 2 months to 2 years. There were 4 operative deaths and 1 patient died later. Seven survivors were followed from 4 to 9 years, and 6 had full postoperative investigations. Relief of troublesome symptoms was constant but persistent cardiomegaly and right heart failure were common. The procedure was considered to be life-saving in the survivors.

\section{REFERENCES}

Albert, H. M., Fowler, R. L., Craighead, C. C., Glass, B. A., and Atik, M. (1961). Pulmonary artery banding. Circulation, 23, 16.
Baron, M. G., Wolf, B. S., Steinfeld, L., and Van Mierop, L. H. S. (1964). Endocardial cushion defects. Specific diagnosis by angiocardiography. Amer. f. Cardiol., $13,162$.

Carr, I., and Wells, B. (1966). Coaxial flow-guided catheterisation of the pulmonary artery in transposition of the great arteries. Lancet, $2,318$.

Dammann, J. F., Jr., McEachen, J. A., Thompson, W. M. Jr., Smith, R., and Muller, W. H., Jr. (1961). The regression of pulmonary vascular disease after the creation of pulmonary stenosis. F. thorac. cardiovasc. Surg., 42, 722 .

Davies, H. (1959). Chest deformities in congenital heart disease. Brit. F. Dis. Chest, 53, 151.

-, Williams, J., and Wood, P. (1962). Lung stiffness in states of abnormal pulmonary blood flow and pressure. Brit. Heart f., 24, 129.

Fowler, R. L., Albert, H. M., Novick, R., Puyau, F. A., and Craighead, C. C. (1958). Response of infants with large ventricular septal defects to banding of the pulmonary artery. Circulation, 18, 720.

Gammelgaard, A., Therkelsen, F., Boesen, I., and Terslev, E. (1961). Ventricular septal defects in infancy treated with surgical narrowing of the pulmonary artery. Acta chir. scand. Suppl., 283, p. 84.

Goldblatt, A., Bernhard, W. F., Nadas, A. S., and Gross, R. E. (1965). Pulmonary artery banding: indications and results in infants and children. Circulation, 32, 172.

Morrow, A. G., and Braunwald, N. S. (1961). The surgical treatment of ventricular septal defect in infancy. Circulation, 24, 34.

Muller, W. H., Jr., and Dammann, J. F., Jr. (1952a). The surgical significance of pulmonary hypertension. Ann. Surg., 136, 495.

$\longrightarrow$, and $-(1952 \mathrm{~b})$. The treatment of certain congenital malformations of the heart by the creation of pulmonic stenosis to reduce pulmonary hypertension and excessive pulmonary blood flow. Surg. Gynec. Obstet., 95, 213.

Sirak, H. D., Hosier, D. M., and Clatworthy, H. W., Jr. (1959). Defects of the interventricular septum in infancy. A two-stage approach to their surgical correction. New Engl. F. Med., 260, 147.

Somerville, J. (1965). Ostium primum defect: Factors causing deterioration in the natural history. Brit. Heart f., 27, 413.

- (1966a). Clinical assessment of the function of the mitral valve in atrioventricular defects related to the anatomy. Amer. Heart F., 71, 701.

- (1966b). M.D. Thesis, London.

- , and Jefferson, K. (1967). Left ventricular angiocardiography in atrioventricular defects. (Abstract.) Brit. Heart f., 29, 939.

Stark, J., Aberdeen, E., and Waterston, D. J. (1967). Pulmonary artery constriction : 146 cases. F. pediat. Surg. In the press. 